\title{
EDITORIAL
}

\section{Observational trials in pulmonary arterial hypertension: low scientific evidence but high clinical value}

\author{
M.M. Hoeper
}

西 $\mathrm{n}$ this issue of the European Respiratory Journal, MATHAI et al. [1] (from Johns Hopkins University, Baltimore, MD, USA) report on their experience with the use of sildenafil, a phosphodiesterase-5 inhibitor, in patients with pulmonary arterial hypertension (PAH) who failed monotherapy with bosentan, an endothelin receptor antagonist. Within a 4-yr period, 82 patients with either idiopathic PAH (IPAH) or PAH associated with systemic sclerosis (PAH-SSc) were treated with bosentan. Among those, $13 \mathrm{IPAH}$ patients and $12 \mathrm{PAH}-\mathrm{SSc}$ patients showed signs of clinical worsening such that sildenafil was added to bosentan. Although haemodynamic parameters were similar at baseline, the median time from initiation of bosentan treatment to clinical worsening was 792 days in the IPAH group but only 458 days in the PAH-SSc group. The clinical response to combination therapy was mixed: in IPAH patients, the 6-min walk distance improved by $47 \pm 77 \mathrm{~m}$, whereas in PAH-SSc patients the 6-min walk distance deteriorated by $-7 \pm 40 \mathrm{~m}$. During follow-up, only one IPAH patient needed additional therapy (intravenous treprostinil), whereas five PAH-SSc patients required further escalation of treatment by addition of either inhaled or intravenous prostanoids. Death occurred in one IPAH patient (from gastro-intestinal bleeding unrelated to PAH) and in four patients with PAH-SSc. MATHAI et al. [1] thus concluded that addition of sildenafil to bosentan was more effective in patients with IPAH than in patients with PAH-SSc and that additional studies are needed to assess safety and efficacy of this combination in the latter group of patients.

Although this study is limited by its small sample size and the lack of a control group, it has some clinical implications. First, it confirms previous findings that adding sildenafil to bosentan is safe and efficacious in patients with IPAH [2]. Secondly, it underscores the notion that it may not be prudent to lump together several forms of PAH in clinical trials.

Do these results suggest that the combination of bosentan and sildenafil should be used in patients with IPAH but not in those with PAH-SSc? The answer is: we don't know for sure. As mentioned above, there are a growing number of uncontrolled studies suggesting that this combination has beneficial effects in IPAH [2, 3], but results from controlled trials are missing. For PAH-SSc, the data from MATHAI et al. [1]

\section{STATEMENT OF INTEREST: None declared.}

CORRESPONDENCE: M.M. Hoeper, Dept of Respiratory Medicine, Hannover Medical School, CarlNeuberg-Str. 1, 30625 Hannover, Germany. Fax: 49 5115328536. E-mail: hoeper.marius@ mh-hannover.de are pretty much all we have for the time being but a series of 12 patients is clearly too small to allow definitive conclusions.

In any case, these data remind us once again that not all types of $\mathrm{PAH}$ respond in the same way to medical therapy. According to the current classification, PAH comprises a heterogeneous group of diseases, which include IPAH, familial $\mathrm{PAH}$ and PAH associated with distinct conditions such as appetite suppressant use, connective tissue disease, congenital heart disease, HIV infection, portal hypertension and some other entities [4]. Even if these different types of $\mathrm{PAH}$ have similar clinical presentations and share histological features, one would be surprised to find that they all respond in the same way to drug treatment. Most of the major trials in the field have predominantly enrolled patients with IPAH, followed by PAH-SSc and a smaller number of patients with repaired congenital heart disease. Patients with HIV-associated $\mathrm{PAH}$ and those with portopulmonary hypertension have been excluded from almost all major trials in the field.

As in the study by MATHAI et al. [1], one nearly uniform result of the major PAH trials has been that patients with IPAH have better functional improvement in response to medical therapy than patients with PAH-SSc, regardless of the drug under study. This observation has been made with beraprost, an oral prostanoid, for which a significant improvement in 6-min walk distance could be demonstrated only in IPAH patients but not in patients with other forms of PAH [5]. The same is true for inhaled iloprost, which therefore has been approved in Europe only for use in IPAH but not for other forms of PAH [6]. In the pivotal bosentan trial (Bosentan Randomized trial of Endothelin Antagonist Therapy (BREATHE)-1), the placebocorrected effects on 6-min walk distance appeared similar in patients with IPAH and those with PAH-SSc but this effect was mainly driven by clinical improvement in IPAH patients, whereas bosentan-treated PAH-SSc patients had no significant change from baseline while the placebo group experienced substantial deterioration [7]. In the Sildenafil Use in Pulmonary Arterial Hypertension (SUPER)-1 trial, which compared three dosing regimens of sildenafil with placebo, IPAH patients had significant improvements in 6-min walk distance with all three dosages, i.e. 20, 40 and $80 \mathrm{mg}$ t.i.d., respectively, whereas in PAH-SSc patients sildenafil caused significant improvements only at 20 and $40 \mathrm{mg}$ t.i.d. but paradoxically not at $80 \mathrm{mg}$ t.i.d. [8]. More importantly, observational case series strongly suggest that the long-term outcome of PAH-SSc patients is substantially worse than that of any other PAH subpopulation (perhaps with the exception of pulmonary veno-occlusive disease), regardless of which treatment is being used [9]. 
PAH-SSc is a good example of the evolving complexities in the field of pulmonary hypertension. Several drugs have now been approved but we cannot be sure that the results of the large clinical trials apply in the same way to all subtypes of PAH. We don't know the best treatments for individual patients since head-to-head comparison studies have not been performed. Perhaps one treatment may work better in one form of $\mathrm{PAH}$, while another treatment may be better suited to another type of pulmonary hypertension. There are a rapidly increasing number of active treatments but, for most of them, there is not sufficient information about their long-term efficacy. There are no solid data to guide us on how to treat patients with rare forms of $\mathrm{PAH}$, not to mention other forms of pulmonary hypertension. Finally, there is only limited information on the safety and efficacy of combination therapy for PAH and most of the trials that have been published so far have looked only at short-term effects, although long-term data are desperately needed [10-14]. Results from the only long-term randomised combination therapy trial that is currently ongoing, COMPASS-2 (sildenafil plus bosentan versus placebo as addon therapy), will be available in 2010 or later. At best, this trial may provide convincing evidence that the combination of sildenafil and bosentan results in better long-term outcome than sildenafil monotherapy, but it will not give us any information as to whether this combination is more or less efficacious than others. It is even possible that the results of this trial may be of minor importance when they become available given the rapid development of novel treatments for PAH.

Since it is practically impossible to obtain answers to all of these questions for the various subtypes of pulmonary arterial hypertension from randomised controlled trials, it becomes clear that well-conducted observational studies like the one by MATHAI et al. [1] will remain a major and valuable source of information for clinicians, even if the grade of evidence is low and the scientific value remains limited. In fact, some of the most relevant data currently available have been derived not from formal trials but from large pulmonary hypertension centres presenting long-term experiences with their therapeutic concepts. Without observational and uncontrolled trials, we would know nothing about which patients derive long-term benefit from calcium-channel blockers [15], nothing about long-term efficacy of current treatments [16-20] and nothing about the therapeutic value of the novel substances in rare forms of pulmonary arterial hypertension [21-23]. Thus, observational studies will remain an important source of valuable clinical information in the future. The large pulmonary hypertension centres should continue their efforts to develop treatment strategies and to study the long-term results in different pulmonary arterial hypertension populations. It may even be possible to obtain controlled data outside the setting of formal trials if large centres collaborate and combine their efforts. Intelligent strategies need to be developed to avoid the many caveats of nonrandomised trials [24].

\section{REFERENCES}

1 Mathai SC, Girgis RE, Fisher MR, et al. Addition of sildenafil to bosentan monotherapy in pulmonary arterial hypertension. Eur Respir J 2007; 29: 469-475.
2 Hoeper MM, Faulenbach C, Golpon H, Winkler J, Welte T, Niedermeyer J. Combination therapy with bosentan and sildenafil in idiopathic pulmonary arterial hypertension. Eur Respir J 2004; 24: 1007-1010.

3 Minai OA, Arroliga AC. Long-term results after addition of sildenafil in idiopathic PAH patients on bosentan. South Med J 2006; 99: 880-883.

4 Simonneau G, Galie N, Rubin LJ, et al. Clinical classification of pulmonary hypertension. J Am Coll Cardiol 2004; 43: Suppl. 12, 5S-12S.

5 Galie N, Humbert M, Vachiery JL, et al. Effects of beraprost sodium, an oral prostacyclin analogue, in patients with pulmonary arterial hypertension: a randomized, doubleblind, placebo-controlled trial. J Am Coll Cardiol 2002; 39: 1496-1502.

6 Olschewski H, Simonneau G, Galie N, et al. Inhaled iloprost for severe pulmonary hypertension. $N$ Engl J Med 2002; 347: 322-329.

7 Rubin LJ, Badesch DB, Barst RJ, et al. Bosentan therapy for pulmonary arterial hypertension. N Engl J Med 2002; 346: 896-903.

8 Galie N, Ghofrani HA, Torbicki A, et al. Sildenafil citrate therapy for pulmonary arterial hypertension. N Engl J Med 2005; 353: 2148-2157.

9 Kuhn KP, Byrne DW, Arbogast PG, Doyle TP, Loyd JE, Robbins IM. Outcome in 91 consecutive patients with pulmonary arterial hypertension receiving epoprostenol. Am J Respir Crit Care Med 2003; 167: 580-586.

10 Humbert M, Barst RJ, Robbins IM, et al. Combination of bosentan with epoprostenol in pulmonary arterial hypertension: BREATHE-2. Eur Respir J 2004; 24: 353-359.

11 Hoeper MM, Leuchte $H$, Halank $M$, et al. Combining inhaled iloprost with bosentan in patients with idiopathic pulmonary arterial hypertension. Eur Respir J 2006; 28: 691-694.

12 Gomberg-Maitland M. Learning to pair therapies and the expanding matrix for pulmonary arterial hypertension: is more better? Eur Respir J 2006; 28: 683-686.

13 Humbert M. Improving survival in pulmonary arterial hypertension. Eur Respir J 2005; 25: 218-220.

14 McLaughlin VV, Oudiz RJ, Frost A, et al. Randomized study of adding inhaled iloprost to existing bosentan in pulmonary arterial hypertension. Am J Respir Crit Care Med 2006; 174: 1257-1263.

15 Sitbon O, Humbert M, Jais X, et al. Long-term response to calcium channel blockers in idiopathic pulmonary arterial hypertension. Circulation 2005; 111: 3105-3111.

16 Sitbon $\mathrm{O}$, Humbert $\mathrm{M}$, Nunes $\mathrm{H}$, et al. Long-term intravenous epoprostenol infusion in primary pulmonary hypertension: prognostic factors and survival. J Am Coll Cardiol 2002; 40: 780-788.

17 McLaughlin VV, Shillington A, Rich S. Survival in primary pulmonary hypertension: the impact of epoprostenol therapy. Circulation 2002; 106: 1477-1482.

18 Hoeper MM, Markevych I, Spiekerkoetter E, Welte T, Niedermeyer J. Goal-oriented treatment and combination therapy for pulmonary arterial hypertension. Eur Respir J 2005; 26: 858-863.

19 Provencher S, Sitbon O, Humbert M, Cabrol S, Jais X, Simonneau G. Long-term outcome with first-line bosentan 
therapy in idiopathic pulmonary arterial hypertension. Eur Heart J 2006; 27: 589-595.

20 Opitz CF, Wensel R, Winkler J, et al. Clinical efficacy and survival with first-line inhaled iloprost therapy in patients with idiopathic pulmonary arterial hypertension. Eur Heart J 2005; 26: 1895-1902.

21 Hoeper MM, Halank M, Marx C, et al. Bosentan therapy for portopulmonary hypertension. Eur Respir J 2005; 25: 502-508.
22 Reichenberger F, Voswinckel R, Steveling E, et al. Sildenafil treatment for portopulmonary hypertension. Eur Respir J 2006; 28: 563-567.

23 Sitbon O, Gressin V, Speich R, et al. Bosentan for the treatment of human immunodeficiency virus-associated pulmonary arterial hypertension. Am J Respir Crit Care Med 2004; 170: 1212-1217.

24 Vandenbroucke JP. When are observational studies as credible as randomised trials? Lancet 2004; 363: 1728-1731. 